\title{
Resiliência organizacional e inovação sustentável: um estudo sobre o modelo de gestão de pessoas de uma empresa brasileira de energia
}

\section{Organizational resilience and sustainable innovation: a study on the human resources management model at a Brazilian energy company}

Isabella Francisca Freitas Gouveia de Vasconcelos ${ }^{1}$

Fundação Getulio Vargas / Escola Brasileira de Administração Pública e de Empresas - EBAPE, Rio de Janeiro, RJ - Brasil

Alvaro Bruno Cyrino ${ }^{2}$

Fundação Getulio Vargas / Escola Brasileira de Administração Pública e de Empresas - EBAPE, Rio de Janeiro, RJ - Brasil

Lucas Martins D'Oliveira ${ }^{3}$

Petrobras S.A. / Escola de Gestão e Negócios da Universidade Petrobras, Rio de Janeiro, RJ - Brasil

Erik Proença Prallon 4

Fundação Getulio Vargas / Escola Brasileira de Administração Pública e de Empresas - EBAPE, Rio de Janeiro, RJ - Brasil

\section{Resumo}

Este artigo tem por objetivo relacionar o conceito de organização inovadora sustentável com o conceito de resiliência organizacional. Para tanto, foi realizado um estudo no departamento de recursos humanos da EBE S.A., uma empresa brasileira de energia. Este trabalho realiza uma revisão teórica dos conceitos de visão baseada em recursos, competências essenciais, capacidades dinâmicas, modelo estratégico de gestão de pessoas, aprendizagem organizacional, resiliência organizacional, organização inovadora sustentável e, por fim, identifica quais são as práticas da gestão de pessoas da EBE S.A. que contribuem para que a empresa seja uma Organização Inovadora Sustentável Resiliente.

Palavras-chave: Gestão estratégica de pessoas. Resiliência. Organização inovadora sustentável.

Artigo recebido em 28 de março de 2015 e aceito para publicação em 15 de setembro de 2015.

DOI: http://dx.doi.org/10.1590/1679-395155896

${ }^{1}$ Doutora em Administração pela HEC - Ecole dês Hautes Etudes Commerciales, França; Professora Dra. Adjunta da FGV / EBAPE; Professora associada e pesquisadora do LIRSA - Laboratorio Interdisciplinaire de Recherches en Sciences de L'Action, CNAM Paris/França e Coordenadora do Centro Franco - Brasileiro de Estudos Avançados em Organizações, Inovação e Sustentabilidade. Endereço: Praia de Botafogo, 190 - 5o andar - Botafogo, CEP 22250-900, Rio de Janeiro, RJ - Brasil. E-mail: isabella.vasconcelos@fgv.br

${ }^{2}$ Doutor em Estratégia e Política de Empresas pela HEC - Ecole de Hautes Etudes Commerciales, França; Vice-diretor e Professor Dr. Adjunto da FGV / EBAPE. Endereço: Praia de Botafogo, 190 - 5 Andar - Botafogo, CEP 22250-900, Rio de Janeiro, RJ -Brasil. Email: alvaro.cyrino@fgv.br

${ }^{3}$ Mestre em Administração pela FGV / EBAPE; Professor e pesquisador da Escola de Gestão e Negócios da Universidade Petrobras; Pesquisador associado do Centro Franco - Brasileiro de Estudos Avançados em Organizações, Inovação e Sustentabilidade. Endereço: Rua Ulysses Guimarães, 565 - 8o andar - Cidade Nova, CEP 20211-225, Rio de Janeiro, RJ - Brasil. E-mail: lucasmdo@petrobras.com.br

${ }^{4}$ Graduando em Administração de Empresas pela FGV / EBAPE; Assistente de Pesquisa da FGV / EBAPE; Pesquisador associado do Centro Franco - Brasileiro de Estudos Avançados em Organizações, Inovação e Sustentabilidade. Endereço: Praia de Botafogo, 190 $5^{\circ}$ Andar - Botafogo, CEP 22250-900, Rio de Janeiro, RJ -Brasil. E-mail: erik.prallon2014@fgvmail.br 


\begin{abstract}
This article aims to relate the concept of sustainable innovative organization to the concept of organizational resilience. To do this, a study was carried out at the human resources department of EBE S.A., a Brazilian energy company. This paper conducts a theoretical review of the concepts of resource-based vision, core competencies, dynamic capabilities, strategic human resources management, learning organization, organizational resilience, sustainable innovative organization, and, finally, it identifies which are the human resources management practices of EBE S.A. that contribute to make the company a Resilient Sustainable Innovative Organization.
\end{abstract}

Keywords: Strategic management of people. Resilience. Sustainable innovative organization.

\title{
Referencial teórico
}

A seguir, são apresentadas algumas teorias necessárias para entender o conceito de Organização Inovadora Sustentável e o conceito de Resiliência Organizacional. Posteriormente, são apresentados esses dois conceitos separadamente e de forma integrada.

\section{Análise das Capacidades Internas - Visão Baseada em Recursos (VBR)}

A visão baseada em recursos (VBR) sugere que uma empresa pode obter vantagens competitivas sustentáveis, e alcançar maior desempenho, quando consegue utilizar seus recursos e suas capacidades para formular e implementar estratégias que criem um valor que não pode ser oferecido por outra empresa concorrente no mercado, simultaneamente (BARNEY, 1991).

O modelo derivado da VBR, que é utilizado para analisar as forças e fraquezas internas de uma empresa, é chamado modelo VRIO, e sugere que os recursos e as capacidades de uma organização devem ser analisados conforme quatro perspectivas, para avaliar seu potencial competitivo, são elas: o valor, a raridade, a imitabilidade, e a organização da empresa (BARNEY e HESTERLY, 2011).

De acordo com Barney (1991), os recursos e as capacidades de uma empresa são valiosos quando lhe permitem explorar oportunidades e/ou neutralizar ameaças externas. São raros quando são gerenciados por um número reduzido de organizações concorrentes. São difíceis de imitar quando as organizações concorrentes enfrentam custos altos para adquiri-los ou desenvolvê-los. E são organizáveis quando as políticas e procedimentos da empresa estão sistematizados para fornecer suporte à exploração de seus recursos (BARNEY e HESTERLY, 2011).

Assim, é possível observar de que modo a gestão eficiente dos recursos e das capacidades de uma organização pode impactar de maneira positiva sua escolha estratégica e seu desempenho no mercado, gerando, com isso, vantagens competitivas para a empresa. Por outro lado, dada a natureza complexa e hipercompetitiva dos mercados, que estão em constante mudança e transformação, o fato de conhecer e gerenciar de forma eficiente recursos e capacidades poderá garantir, no limite, apenas vantagens competitivas temporárias.

Assim, parece razoável supor que para obter vantagens competitivas sustentáveis, em mercados em contínua transformação, a empresa precisará identificar as competências essenciais para seu negócio, bem como estruturar seus processos de modo a garantir a renovação constante de seu portfólio de recursos, a fim de garantir certa dinamicidade às suas capacidades, de modo que elas possibilitem a adaptação da organização a cada novo cenário que se apresente no mercado. 


\section{Competências Essenciais e Capacidades Dinâmicas}

De acordo com Pelaez, Aquino, Hofmann et al. (2009), a comprovação de que o acúmulo de recursos não é suficiente para garantir vantagens competitivas sustentáveis está na importância que é dada à capacidade da empresa de coordenar capacidades internas e externas de maneira a se adaptar a mercados em constante transformação. Nesse contexto, torna-se essencial entender a natureza dinâmica que as capacidades organizacionais devem possuir a fim de garantir a perenidade das empresas. Capacidade dinâmica seria a capacidade de reconfigurar, redirecionar, transformar, moldar adequadamente e integrar competências essenciais existentes com recursos externos e ativos estratégicos para enfrentar os desafios, criando a competência de mudar rapidamente dentro de um contexto schumpeteriano, isto é, complexo e turbulento de competição e imitação (TEECE, PISANO e SHUEN, 1997).

De acordo com a perspectiva schumpeteriana, a obtenção de vantagens competitivas seria determinada essencialmente pela capacidade da organização de inovar, a qual tende a ser continuamente desafiada pelo dinamismo tecnológico dos mercados e de seus concorrentes, essa capacidade dependeria tanto do conhecimento científico-tecnológico que a empresa possui, quanto da sua capacidade em coordenar seus recursos por meio de sua estrutura organizacional (PELAEZ, AQUINO, HOFMANN et al., 2009).

A competição entre empresas, originalmente focada na análise dos mercados e dos produtos, passaria, então, a ser analisada em função dos recursos únicos e/ou raros que resultam dos processos organizacionais específicos de cada empresa (VASCONCELOS e CYRINO, 2000). Com isso, a noção tradicional de competição centrada em produtos e serviços passaria para uma competição baseada nas competências (competence-based competition) das organizações (PRAHALAD e HAMEL, 1990).

As mudanças ambientais costumam exigir que as organizações renovem, de forma constante, seu portfólio de recursos e competências, de forma a garantir sua sobrevivência e um desempenho econômico diferenciado das demais empresas (VASCONCELOS e CYRINO, 2000). Seria por meio da antecipação das mudanças nas bases de recursos que as empresas conseguiriam garantir a possibilidade de obter vantagens competitivas sustentáveis (AMIT e SCHOEMAKER, 1993).

Segundo Vasconcelos e Cyrino (2000), a teoria das capacidades dinâmicas trabalha com as suposições de que nem todas as competências são igualmente importantes para a vantagem competitiva, bem como determinada empresa somente poderá se destacar em uma quantidade relativamente restrita de competências, estas definidas como competências essenciais (core competencies).

De acordo com Prahalad e Hamel (1990), as competências essenciais seriam a origem da competitividade, em mercados inexistentes e futuros, considerando que a oportunidade de identificar suas competências ofereceria à organização as condições necessárias para realizar investimentos, alocando seus recursos e capacidades de maneira estratégica.

Como já foi dito, para obter vantagens competitivas sustentáveis, em mercados em contínua mutação, a organização necessita identificar suas competências centrais e adequar seus processos internos de maneira a facilitar a constante regeneração de sua base de recursos.

\section{Gestão por Competências}

Para Moura e Bitencourt (2006), a efetividade da empresa estaria diretamente relacionada à sua capacidade de articular a escolha estratégica com as competências organizacionais, dos grupos e as individuais. Dessa forma, segundo as autoras, ao estabelecer um direcionamento estratégico e alinhá-lo às competências organizacionais, desdobrando as competências em coletivas e individuais, a empresa precisaria refletir sobre a cultura e o modelo de gestão. 
Dutra (2001) ressalta que a competência pode ser compreendida como um conjunto de conhecimentos, habilidades e atitudes necessários para que a pessoa desenvolva suas atribuições, sendo que isso, per se, não garante que a organização se beneficiará diretamente das competências aparentemente à sua disposição.

Segundo Hamel e Prahalad (1994), para obter vantagem competitiva sustentável, a organização precisa inovar de forma contínua. Para tanto, deve promover o mapeamento e alinhamento de suas competências organizacionais e individuais às competências essenciais (core competencies) que definir como estratégicas.

Assim, alinhar e adequar as competências ao modelo VRIO, apresentado anteriormente, passa a ser fundamental e, para que isso ocorra, torna-se necessário adotar um modelo de gestão de pessoas por competências, também chamado modelo estratégico de gestão de pessoas ou, ainda, de modelo político.

\section{Modelo Estratégico de Gestão de Pessoas}

Em mercados em constante mudança, para criar vantagens competitivas sustentáveis, a organização precisa identificar suas competências essenciais e adequar seus processos internos de modo a facilitar a contínua regeneração de seu portfólio de recursos. Para tanto, torna-se fundamental desenvolver competências e alinhá-las em todos os níveis organizacionais, de forma a inovar continuamente as práticas e os processos organizacionais a fim de desenvolver capacidades dinâmicas, que suportem a necessidade de adaptação contínua da empresa diante das mudanças ambientais, possibilitando o alcance de vantagens competitivas sustentáveis.

Nesse contexto, a aquisição, o desenvolvimento e a gestão de competências passam a representar um fator importante na estratégia e na competitividade empresarial. Partindo da premissa de que as competências essenciais, ou seja, uma das principais fontes de vantagem competitiva da organização, representariam o resultado da combinação de competências organizacionais, as quais derivariam da combinação de competências de grupos, que, por fim, teriam sua origem na combinação de competências individuais, poderse-ia constatar que o indivíduo passa a ser tratado não apenas como mais um recurso da empresa, mas, sim, como o principal fator que pode trazer vantagem competitiva sustentável por meio do desenvolvimento de suas competências.

A visão baseada em recursos foca nas capacidades internas, que se agregarem valor, forem raras, e difíceis de imitar, podem representar a base para que a organização possa obter vantagens competitivas sustentáveis (LACOMBE e CHU, 2008). Nesse sentido, organizações estruturadas por competências, que representariam um recurso interno especial, devem ser capaz de articular e integrar cada política de recursos humanos (RH) com seus objetivos estratégicos (DUTRA, 2001).

Assim, a empresa precisa adotar uma gestão que tenha um olhar diferente do modelo tradicional da gestão de pessoas, considerando que a base para essa mudança está relacionada com o desenvolvimento de competências estratégicas e com seu alinhamento com os processos, as políticas, as práticas de gestão de pessoas e, por fim, com seus objetivos estratégicos (MOURA e BITENCOURT, 2006).

Em um modelo estratégico de gestão de pessoas, as práticas de recrutamento e seleção de pessoas devem buscar o desenvolvimento do potencial do indivíduo em início de carreira, ao mesmo tempo que o recrutamento interno deve se dirigir para valorizá-lo em níveis mais avançados (ALBUQUERQUE, 1999). Para o autor, as políticas de capacitação não devem se restringir somente ao aumento de desempenho do indivíduo na função atual, mas estar mais focada no desenvolvimento de competências que aumentem as capacidades do indivíduo em gerar valor para a organização no longo prazo, considerando outras funções que ele mesmo pode assumir ao longo da carreira. Com isso, a capacitação deve focar nos processos de aprendizagem individual, coletiva e organizacional e as necessidades decorrentes da introdução de inovações e de mudanças organizacionais (FLEURY e FLEURY, 2004). 
Nessa nova perspectiva, na qual o perfil e a relevância do indivíduo para a empresa sofrem mudanças significativas, e o desenvolvimento de competências organizacionais e individuais passa a ser o foco principal da gestão estratégica de pessoas, torna-se fundamental não apenas quantificar progressos escalonados de competências, mas também compreender como ocorrem as aprendizagens individuais, coletivas e organizacionais (MOURA e BITENCOURT, 2006).

\section{Aprendizagem Organizacional e Inovação}

De acordo com Lei, Hitt e Bettis (2001), a transição entre a teoria dos recursos e a teoria das capacidades dinâmicas tende a reposicionar o processo de aprendizagem organizacional como base da administração estratégica. Nesse novo cenário, a habilidade da organização em se estruturar como sistema integrado de aprendizagem contribuiria para a implementação de uma estratégia mais dinâmica e adequada às atuais características do ambiente competitivo (LEONARD-BARTON, 1992). Desse modo, os processos de aprendizagem deveriam estar cada vez mais presentes, de forma integrada, nas diversas esferas da empresa, permeando as dimensões organizacionais, coletivas e individuais (MOURA e BITENCOURT, 2006).

Na medida em que a estratégia esteja relacionada a uma abordagem mais prescritiva, poder-se-ia prever certo determinismo acerca das competências essenciais e organizacionais que garantiriam a operação organizacional (MOURA e BITENCOURT, 2006). Por outro lado, a compreensão da estratégia sob o foco da aprendizagem organizacional permitiria entender de que modo a empresa compreende o contexto à sua volta conforme se confronta com obstáculos e desafios, buscando alternativas (MINTZBERG, AHISTRAND e LAMPEL, 1998).

A aprendizagem no modelo político estaria relacionada ao conceito de aprendizagem em circuito duplo (double looping learning), que, segundo Argyris (1992), estaria associado à percepção e exploração do ambiente pelo indivíduo por meio do acesso a novas informações, as quais seriam comparadas com as regras e processos atuais dos sistemas produtivos, com o objetivo de refletir sobre a pertinência ou não do conjunto de normas vigentes, bem como o de implementar ações corretivas necessárias, ou seja, reconfigurando o próprio sistema. Segundo o autor, no âmbito organizacional, a aprendizagem em circuito duplo implicaria questionamento contínuo das bases de configuração de um dado sistema produtivo, por meio da obtenção de novas informações, considerando redesenhar e/ou modificar de forma relevante os processos, a tecnologia ou a própria organização, se necessário. No que tange ao âmbito do indivíduo, o autor ressalta que esse tipo de aprendizagem traria à pessoa uma necessidade de questionar as próprias maneiras de comportar-se, optando por mudar quando fosse preciso.

Vasconcelos, Mascarenhas e Vasconcelos (2004) observam que o modelo político de gestão de pessoas estaria mais próximo do modelo de organização em aprendizagem que, nesse contexto, poderia estar associado à criação de um "sistema fracamente articulado" (loosely coupled systems), o qual, segundo Weick (1995), permitiria a diversidade cultural e o debate entre indivíduos com diferentes representações da realidade, favorecendo a criação de várias opções de ação ao questionar o status quo, e sendo fonte de aprendizado, desenvolvimento de competências e inovação. Para Weick (1995), o sistema fracamente articulado preserva as diversas identidades e particularidades de cada um dos subsistemas organizacionais, possibilitando, desse modo, a manutenção de diferentes padrões culturais que, ao conviver juntos e de forma pacífica, podem ser usados como base para mudanças mais complexas, que demandem soluções inovadoras.

\section{Resiliência Organizacional}

A resiliência organizacional é a habilidade organizacional de lidar com recuperação, adaptação rápida e mudança eficaz de eventos disruptivos (como mudanças produzidas pela inovação real) em um círculo virtuoso, atingindo rapidamente um estado produtivo para o crescimento e o desenvolvimento em um nível organizacional mais complexo. Reengenharia radical significa inovação com ruptura tecnológica, organizacional, e redesenho dos papéis sociais de forma a romper com os modelos anteriores e inovar 
completamente. A melhoria contínua implica somente melhoria incremental e progressiva dos processos e produtos existentes na organização atualmente (FIKSEL, 2003).

Em busca do valor, raridade e imitabilidade de seus recursos, produtos e serviços, a organização inovadora sustentável vai tentar implementar a gestão estratégica de pessoas para promover a inovação radical sustentável (reengenharia radical dos produtos e serviços com preocupação com a sustentabilidade). Reengenharia radical vai implicar uma série de inovações com ruptura tecnológica, redesenho radical (reengenharia) dos serviços e produtos da organização e redesenho dos processos organizacionais. Inovações sucessivas implicam, pois, diversas rupturas organizacionais e tecnológicas e na evolução para um sistema mais complexo e a adaptação rápida em um novo patamar sistêmico (FIKSEL, 2006). Logo, implica mudanças radicais contínuas. Mudanças contínuas quando efetuadas com resiliência organizacional trazem readaptação rápida e recuperação de situações de ruptura tecnológica e organizacional. A organização necessita, então, de indivíduos resilientes e também precisa desenvolver essa competência da resiliência tanto no nível dos indivíduos quanto no nível sistêmico (BURNARD e BHAMRA, 2011). A organização inovadora sustentável vai promover a inovação radical sustentável com responsabilidade social, preocupando-se com o impacto social, ambiental e econômico dos produtos e serviços na sociedade.

\section{Organização Inovadora Sustentável}

O modelo de organização inovadora sustentável é uma resposta às pressões institucionais por uma organização que seja capaz de inovar com eficiência econômica, social e ambiental. Esse tipo de organização reúne duas características essenciais: é inovadora e orientada para a sustentabilidade. Ou seja, institucionaliza-se uma nova lógica de pesquisa, desenvolvimento e inovação na qual a sustentabilidade e a inovação caminham juntas. A dimensão social tem preocupação com os impactos sociais das inovações nas comunidades humanas dentro e fora da organização. A dimensão ambiental preocupa-se com os impactos ambientais causados pelo uso de recursos naturais e pelas emissões de poluentes. E a dimensão econômica preocupa-se com a eficiência econômica, obtenção de lucro e de vantagens competitivas nos mercados em que atuam (BARBIERI, VASCONCELOS, ANDREASSI et al., 2010).

Então, para que a organização seja considerada inovadora sustentável, ela tem que ser capaz de inovar continuamente e de obedecer a essas três dimensões da sustentabilidade.

A organização inovadora sustentável vai realizar mudanças tendo em vista sucessivas inovações radicais (redesenho radical - reengenharia), inovação tecnológica e redesenho dos processos organizacionais. Essas mudanças sucessivas vão gerar diversas rupturas tecnológicas e organizacionais, levando a organização para um novo nível sistêmico mais complexo. Só que, para isso e para ter sucesso, a organização precisa ser capaz de readaptar-se e recuperar-se, rapidamente, de eventos disruptivos. Ou seja, para promover uma organização inovadora sustentável é preciso que essa organização tenha uma gestão resiliente. Assim, uma organização inovadora sustentável precisa ser também uma organização resiliente.

\section{Problemática}

A problemática deste trabalho é a seguinte: quais são as características que fazem da EBE S.A. uma Organização Inovadora Sustentável Resiliente? 


\section{Objetivo geral}

Realizar um diagnóstico de qual é o modelo de gestão de pessoas predominante na organização estudada, e quais são os principais desafios na consolidação do modelo de gestão de pessoas por competências nessa mesma organização, na visão dos entrevistados.

\section{Objetivos Específicos}

1. Definir os principais conceitos a ser utilizados neste trabalho, em especial os conceitos de gestão de pessoas por competências.

2. Definir a metodologia de estudo de caso com a utilização de técnicas etnográficas a ser aplicadas na pesquisa.

3. Responder à problemática enfatizando as soluções oferecidas pelos entrevistados necessárias à consolidação do modelo.

\section{Metodologia}

A metodologia a ser utilizada neste estudo está relacionada ao método qualitativo. Tal escolha justifica-se pelo fato de tratar-se de uma pesquisa de natureza exploratória, visto que será realizada em uma empresa na qual existe pouco conhecimento acumulado e sistematizado sobre a correlação dos temas abordados (VERGARA, 2013), e pelo fato dos objetivos do trabalho serem o de apreender uma situação in loco, a fim de estabelecer comparações com outros eventos semelhantes e com um referencial teórico construído previamente.

A fim de responder à problemática elaborada nesta pesquisa, opta-se por utilizar a metodologia de estudo de caso, tendo em vista que tal método seria mais adequado quando se pretende estudar uma situação em que os fenômenos são amplos e difíceis de desenredar, a temática é pouco conhecida no contexto estudado, encontrando-se ainda em estágio de maturação da teoria (EISENHARDT, 1989; YIN, 2010). Assim, será aplicado um estudo de caso único, tendo em vista ser o método mais adequado à problemática proposta, bem como ao tempo e aos recursos disponíveis.

Optou-se pela utilização de técnicas etnográficas, por entender que tais técnicas auxiliam o desenvolvimento do estudo de caso ao descrever eventos e situações que ocorrem no cotidiano de um grupo, dando atenção especial às estruturas sociais e ao comportamento das pessoas como membros desse grupo, bem como à interpretação dos significados que os eventos possuem para a cultura desse grupo, o que está de acordo com o pensamento de Godoy (1995).

A fim de definir os conceitos que serão tratados no estudo de caso, é necessária a realização da pesquisa bibliográfica, abrangendo temas como estratégia, visão baseada em recursos, capacidades dinâmicas, gestão de pessoas por competências, aprendizagem organizacional e inovação.

\section{Universo e Amostra}

Para este trabalho, a unidade estudada será o departamento de RH da EBE S.A., uma empresa brasileira de energia com atuação global.

A unidade objeto deste estudo possui sete gerências gerais, ligadas diretamente ao diretor de $\mathrm{RH}$, cerca de 40 gerentes intermediários, e 300 empregados, todos ligados ao diretor da área. Do total, foram escolhidos para 
compor a amostra da pesquisa 11 empregados, sendo 4 gerentes intermediários, 3 especialistas de RH e 4 analistas de RH. Todos os escolhidos foram entrevistados.

\section{Coleta e Análise de Dados}

A fim de desenvolver uma teoria, os pesquisadores podem conciliar múltiplas técnicas e métodos distintos de coleta de dados, para o estudo de caso seria plausível utilizar uma combinação entre pesquisa documental, entrevistas, questionários e observações (EISENHARDT, 1989). Os instrumentos de coleta de dados a ser utilizados, aqui, serão dados primários e secundários da unidade estudada, a observação direta e participante, e a entrevista aberta (semiestruturada).

A coleta de dados estrutura-se da seguinte forma:

1. Análise documental (fontes primárias e secundárias).

2. Observação direta e participante.

3. Entrevistas semiestruturadas, com perguntas abertas.

4. Categorização dos dados obtidos, por meio da manutenção de um fichário com observações.

\section{Apresentação da empresa analisada}

A EBE S.A. é uma empresa brasileira de economia mista, e que está presente em diversos estados do Brasil e em outros países. Com grande dispersão geográfica de suas atividades, atua de maneira integrada no mercado nacional e internacional, na indústria de energia. Diante da expectativa de crescimento, muito por conta do aumento de renda e o consequente aumento da demanda por energia, a EBE S.A. prevê em seu Planejamento Estratégico investimentos em diversas áreas de atuação e regiões do país. Dessa forma, a empresa espera que sua produção atual aumente em 50\% até 2019.

Para que a meta se torne realidade, a EBE S.A., desde 2004, vem investindo no aumento do quadro de empregados, considerando essa visão até 2019. De 2004 até junho de 2014, a quantidade de empregados aumentou cerca de $30 \%$, e espera-se que haja um aumento de mais $20 \%$ até 2019.

Nos próximos anos, um dos grandes desafios das empresas de energia será o de captar, desenvolver e reter pessoas qualificadas em suas atividades, para que elas possam gerar capacidades dinâmicas a partir de seu trabalho, a fim de que as empresas obtenham vantagens competitivas sustentáveis. Atrelado a esse desafio, observa-se que, na EBE S.A., alguns fatores como restrições legais para contratação de novos empregados (segundo o artigo 37 da Constituição Federal do Brasil, o ingresso na EBE S.A. é feito somente por meio de aprovação em processo seletivo público - PSP), a demanda elevada de novas contratações até 2019 e as competências requeridas para cada cargo, podem dificultar o processo de captação e retenção de empregados qualificados, que possam gerar vantagens competitivas sustentáveis para a empresa. Nesse contexto, torna-se premente a necessidade de alinhar os empregados à estratégia da empresa, bem como de implantar um modelo de gestão de pessoas que permita o desenvolvimento de um ambiente que facilite a gestão de competências, a aprendizagem organizacional e a inovação.

O setor de RH, atualmente responsável por coordenar os processos de gestão de pessoas por toda a empresa, deve redobrar sua atenção e seus esforços no sentido de viabilizar a consecução dos objetivos estratégicos da EBE S.A. Nesse sentido, o papel do RH torna-se ainda mais essencial, pois pode alavancar ou dificultar o compartilhamento de conhecimentos entre os profissionais das mais diversas áreas da organização, o desenvolvimento e o monitoramento das competências instaladas, a mobilidade de pessoal entre as áreas e a 
aprendizagem organizacional, o que, consequentemente, pode possibilitar a inovação radical contínua e a criação de vantagens competitivas sustentáveis.

\section{O RH Corporativo}

Para descrever como funciona a unidade RH Corporativo da EBE S.A., serão ressaltadas algumas mudanças que ocorreram entre 2008 e 2013 na empresa, assim como o modelo de gestão de RH, sua estrutura e, por fim, o planejamento estratégico de RH para o período de 2014 a 2019.

\section{De 2008 até 2013}

Em 2008, o Sistema de Educação Empresarial da EBE S.A. (SEE) recebeu credenciamento especial, pelo Ministério da Educação, para a oferta de cursos de especialização em nível de pós-graduação lato sensu nas áreas de Engenharia ligadas ao negócio da empresa. Com isso, os empregados que se formavam nos cursos de formação dessas áreas recebiam, ao final, um diploma, expedido pelo MEC, equivalente a um curso de pós-graduação lato sensu oferecido por universidades e instituições do ensino superior. Além disso, o desenvolvimento de líderes (DL) recebeu especial atenção, com o treinamento de 972 gerentes em 62 turmas dos cursos do Programa de DL, 25\% das participações foram de gerentes recém-designados.

Em 2009, foram investidos cerca de R $\$ 100$ milhões em treinamento do corpo técnico e gerencial, o que se traduziu em mais de quatro milhões de horas de treinamento e em mais de 50 mil participações nos cursos corporativos oferecidos pela Universidade Corporativa (UC). Os esforços de desenvolvimento de RH contribuíram para a sustentabilidade dos negócios, pois pelo quarto ano consecutivo, a EBE S.A. foi considerada referência no critério "Desenvolvimento do Capital Humano", na avaliação do Dow Jones Sustainability Index (DJSI), alcançando a pontuação máxima (100).

Ainda em 2009, houve continuidade no processo de admissões, com o ingresso de aproximadamente 1.000 novos empregados. A entrada sistemática de novos empregados possibilitou à EBE S.A. possuir um efetivo com média de idade de 42 anos, bem abaixo da média mundial da indústria de energia, que é de 50 anos. Tal fato era importante, pois a empresa estava acelerando o processo de transferência de conhecimento a fim de garantir a competitividade e a excelência dos profissionais.

Em 2010, a condução da Gestão do Conhecimento na empresa passou a ser realizada pelo RH Corporativo, então, foi instituída uma nova gerência para cuidar do processo dentro da UC, cujas atribuições eram definir, orientar e assessorar as ações corporativas de gestão do conhecimento na EBE S.A. Os primeiros dois projetos estruturantes implementados foram o Projeto Mentoria, cujo intuito era acelerar o compartilhamento do conhecimento (competências técnicas, cultura, valores, experiências e rede de relacionamento) entre as diferentes "gerações" da empresa por meio de um processo estruturado de mentoria, e o Programa de Sucessão de Líderes, que teve por objetivo preservar a continuidade da liderança.

Nessa época, foi realizado o Programa RH nas Unidades, que consistiu na visita de gerentes do RH Corporativo às unidades operacionais da EBE S.A., e tinha por objetivo a troca de experiências com os gerentes dessas unidades, a fim de ampliar a divulgação dos processos de RH da empresa, a partir de uma visão mais sistêmica.

Em 2011, foram realizados mais dois processos seletivos públicos, com mais de 100 mil candidatos inscritos concorrendo a mais de 800 vagas divulgadas. Além disso, pelo sexto ano consecutivo, a EBE S.A. se manteve na lista das empresas mais sustentáveis do mundo, segundo os critérios do Dow Jones Sustainability Index (DJSI), e a gestão do capital humano teve papel importante nessa conquista.

Nesse mesmo ano, com o objetivo de atualizar os principais desafios e prioridades que se apresentavam à gestão de pessoas, considerando a revisão do Plano Estratégico da EBE S.A. e a perspectiva de evolução e de 
desenvolvimento dos diversos negócios da empresa até 2019, foram elaborados nove temas a ser priorizados na gestão de pessoas: Atração e retenção; Formação de novos líderes e fortalecimento da função gerencial; Gestão do conhecimento orientada para a melhoria dos processos e resultados; Expansão e aceleração da formação e qualificação de mão de obra; Adequação da prestação de serviços; Adequação da mobilidade interna e externa de profissionais; Flexibilização de política, práticas e processos de RH; Cultura de meritocracia; e Sustentabilidade da Assistência Interdisciplinar de Saúde (AIS).

Nessa época, o Modelo de Gestão de Competências foi aperfeiçoado com a realização de melhorias no processo, a expansão dos mapeamentos e diagnósticos de competências e integração com outros processos e sistemas em diversas áreas da empresa. Além disso, foi implantado o Diagnóstico do Líder (DL) para todo o público gerencial com o objetivo de orientar a atuação dos gestores por meio de uma análise estruturada e integrada de processos de RH, visando à melhoria da atuação gerencial.

Ainda em 2011, como parte da consolidação do processo de Gestão do Conhecimento (GC), o RH estabeleceu sua governança e constituiu a Subcomissão de Gestão do Conhecimento, que reúne representantes das diretorias da EBE S.A. e de empresas controladas (subsidiárias) por ela. O objetivo desse fórum era promover a integração e o alinhamento estratégico, propondo e analisando, em âmbito corporativo, diretrizes, metodologias e práticas que proporcionassem a aprendizagem organizacional, inovação e melhoria contínua dos processos de GC na empresa.

Assim, com o propósito de disseminar a gestão do conhecimento na EBE S.A., o RH promoveu, em novembro de 2011, o primeiro evento da Maratona do Conhecimento, com palestras e mesa-redonda, na qual gerentes executivos debateram o tema "O conhecimento como estratégia para a sustentabilidade do negócio". Essa Maratona teve por objetivo promover a reflexão sobre o valor do conhecimento na sociedade atual, reforçando a necessidade de compartilhá-lo na EBE S.A., além de questões como melhoria nos processos, inovação e sustentabilidade. Nesse sentido, o RH sistematizou uma prática de gestão do conhecimento para estimular empregados participantes do Programa de Capacitação no Exterior (PCE) a compartilhar de forma estruturada o conhecimento adquirido, tão logo retornassem de viagem.

Para proporcionar informações de RH de forma ágil e via Internet aos empregados, a área de RH implantou, em 2011, o Blog RH e o SMS RH, cujo público-alvo inicial foram os empregados que trabalhavam embarcados que, por características peculiares de atuação, tinham dificuldades em manter uma comunicação efetiva com o RH. O Blog RH consistiu na criação de um canal para que o empregado tivesse acesso às notícias sobre RH da EBE S.A., a qualquer momento e em qualquer lugar. Além disso, o Blog permitiu acesso aos Comunicados de RH e a outras notícias publicadas na Intranet da EBE S.A. e na aba do RH. Já o SMS RH consistiu na criação de um sistema de cadastro de celulares dos empregados para recebimento de notícias por meio de mensagens.

Em 2012, o RH desenvolveu ações de comunicação para sensibilização sobre o compartilhamento de conhecimentos em toda a EBE S.A., que alcançou um público aproximado de mais de 50.000 empregados, e realizou quatro edições do evento Maratona do Conhecimento, nas cidades de São Paulo, Natal, Salvador e Macaé, que mobilizaram mais de 5.000 pessoas, dentre presentes e espectadores via TV Web. Além disso, o RH deu continuidade aos programas de Mentoria e Disseminação de Conhecimentos do PCE, bem como passou a orientar corporativamente dois novos processos - Lições Aprendidas e Rodízio Técnico - que já eram realizados em algumas unidades da empresa.

Na Universidade Corporativa (UC), foram realizadas mais de 60 mil participações em cursos e seminários, das quais 3.000 em cursos de formação para novos empregados. Houve a inclusão dos cargos de nível médio nos cursos de formação em 2012, resultado de uma importante iniciativa do RH para sustentar a implantação do Planejamento Estratégico da empresa, uma vez que os cargos de nível médio representavam cerca de $60 \%$ do efetivo total da EBE S.A. 
Em 2013, por meio de uma série de eventos com as diversas áreas da empresa, o RH reestruturou seu portfólio de projetos e iniciativas estratégicas. Com isso, cinco temas estratégicos, dentre outros projetos estruturantes, foram priorizados: Reposicionamento da gestão do conhecimento, Planejamento da força de trabalho, Mobilidade, Desenvolvimento estruturado de empregados e Desenvolvimento e sucessão de líderes.

Nesse ano, o RH implementou o Programa Mobilidade, que proporcionou, de forma inédita, a movimentação interna de aproximadamente 1.000 empregados. Seu objetivo foi adequar o efetivo das unidades organizacionais da EBE S.A. ao Plano de Negócios e às estratégias da empresa, buscando compatibilizar as necessidades da EBE S.A. com as dos empregados, mediante condições estabelecidas em regramento específico. O programa foi estruturado em etapas a fim de possibilitar a movimentação de pessoas considerando suas competências com as competências requeridas pela vaga.

Ainda em 2013, foi proposto um novo Modelo de Gestão do Conhecimento (GC) na EBE S.A., além de uma sistemática de atendimento personalizado às áreas da empresa, de modo a auxiliar no planejamento e na implementação das ações de GC. A sustentação do modelo foi fundamentada nos pilares pessoas, processo, liderança e cultura.

Nesse ano, a EBE S.A. investiu mais de R \$ 200 milhões em capacitação de empregados. Foram mais de 200 mil participações em cursos, das quais cerca de 80 mil foram em cursos de formação e educação continuada, promovidos pela UC. Apenas no PCE, foram mais de 1.000 participações. Em média, cada empregado foi treinado cerca de 80 horas ao longo do ano, a média da indústria de energia ficava em torno de 40 horas de treinamento.

As ações do Programa de DL atendem ao objetivo estratégico da empresa de "ter gestores preparados para sustentar a estratégia da EBE S.A.". Dentro das ações de DL, foram identificados, no ano, aproximadamente 300 potenciais gerentes em diferentes áreas e unidades da EBE S.A., dos quais mais de 100 participantes do Programa Potencial Líder assumiram funções gerenciais.

\section{Panorama atual}

Após descrever o período entre 2008 e 2013, e a forma com que a área de RH se desenvolveu ao longo desses anos, será apresentado o atual modelo de gestão e a atual estrutura organizacional do RH Corporativo. Em seguida, será exposto o Planejamento e as Iniciativas Estratégicas de RH 2014-2019, e seus desdobramentos organizacionais.

A diretoria de $\mathrm{RH}$, chamada internamente $\mathrm{RH}$ Corporativo, está subordinada à Diretoria Executiva Corporativa, e tem a responsabilidade de definir políticas, diretrizes e normas corporativas a respeito do modelo de gestão de pessoas a ser seguido em toda a EBE S.A. Por ser uma empresa de grande porte, com atividades complexas e dispersas pelo Brasil e por outros países, a EBE S.A. optou pela adoção de um modelo descentralizado de gestão de RH, no qual o RH Corporativo define e comunica políticas e normas mais gerais para as gerências dos RH Locais, que ficam subordinadas diretamente às demais Diretorias Executivas da empresa, e são responsáveis por executar os processos locais, considerando a subcultura de cada área da empresa, e para as gerências de Serviços de Pessoal e de Serviços de Assistência Interdisciplinar de Saúde (AIS), ambas subordinadas à diretoria de Serviços Compartilhados. A primeira é responsável por operacionalizar os processos de recrutamento e seleção, controle funcional, folha de pagamento e benefícios, enquanto a última é responsável por operacionalizar os processos referentes à AIS.

O RH Corporativo é composto por sete gerências gerais: Clima; Assistência Interdisciplinar de Saúde; Carreira, Recrutamento e Seleção; Planejamento de RH; Relacionamento; Remuneração; e Universidade Corporativa. A seguir, é apresentado o organograma do RH (Figura 1). Além disso, também serão mencionadas as gerências intermediárias, que estão inseridas nas gerências gerais. 
Figura 1

Organograma do RH da EBE S.A.

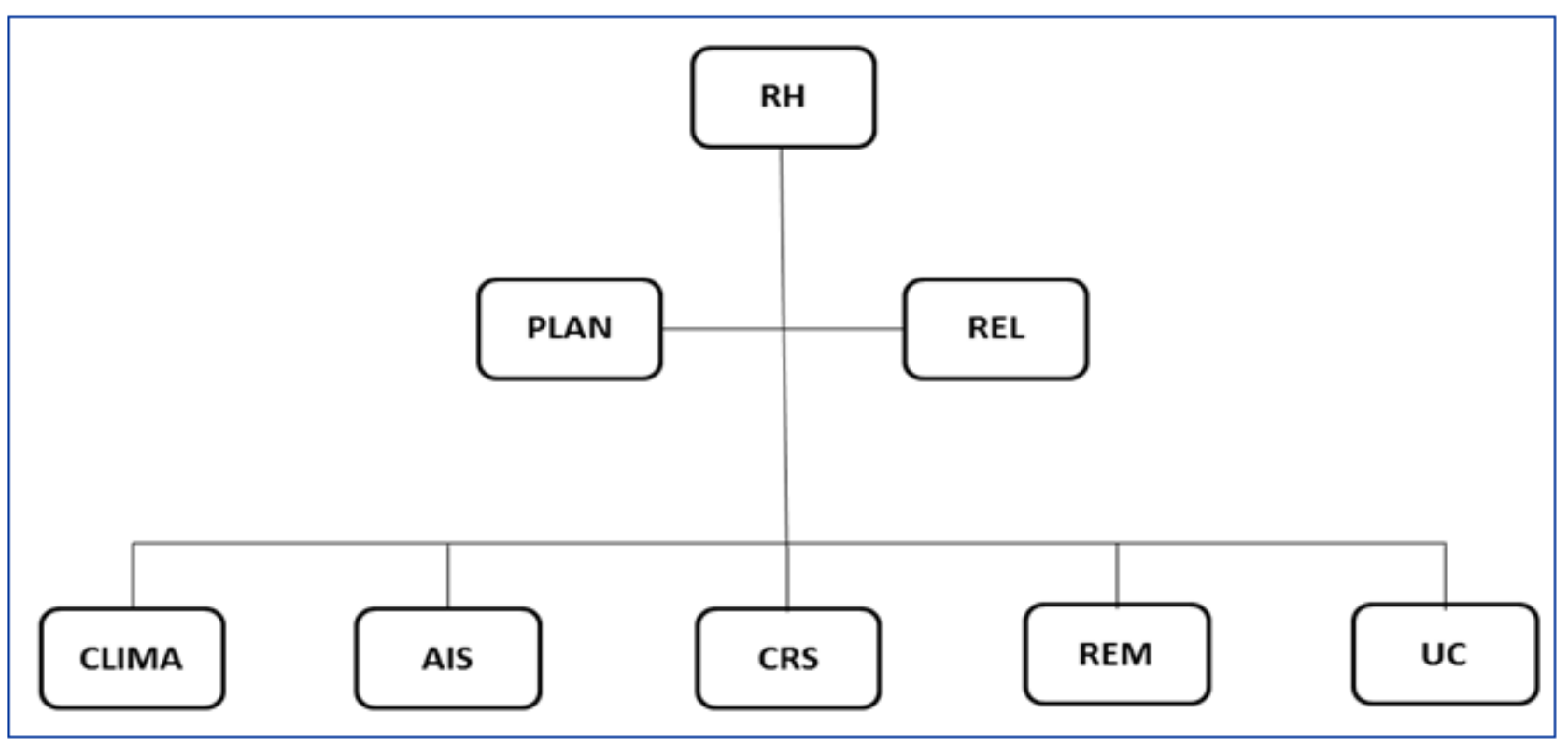

Fonte: Adaptado pelos autores com base no organograma oficial da EBE S.A.

A gerência geral de Clima é responsável por orientar e coordenar as atividades de clima organizacional, comunicação de RH com empregados, relacionamento com entidades sindicais, gestão da ética e responsabilidade social com foco no público interno da EBE S.A. Os principais produtos dessa gerência geral são: Acordo Coletivo de Trabalho (ACT); Pesquisa de Clima; Programa de Preparo para Aposentadoria (PPA); Cultura-Alvo e Valores EBE S.A.; Jornal Recursos Humanos; Informativo RH; Blog de RH; SMS RH (mensagem pelo celular).

A gerência geral de Assistência Interdisciplinar de Saúde (AIS) é responsável por orientar e avaliar a gestão do Plano de Saúde corporativo por meio do desenvolvimento de ações integradas com as diversas unidades da EBE S.A. Os principais produtos dessa gerência geral são: Plano de Saúde AIS (pequeno e grande risco); Benefício Farmácia; Atestado de Saúde Ocupacional (ASO); Portal AIS.

A gerência geral de Carreira, Recrutamento e Seleção (CRS) é responsável por definir e orientar as questões referentes ao dimensionamento, atração, retenção, avaliação e progressão funcional dos empregados da EBE S.A., bem como coordenar a execução desses processos na empresa. Os principais produtos dessa gerência geral são: Edital para Processo Seletivo Público; Avaliação de Perfil e Competências de novos empregados; Dimensionamento de Efetivo de Pessoal; Avanço de Funcional e Promoção (AFPR); Avaliação de Desempenho (AD).

A gerência geral de Planejamento de RH (PLAN) é responsável por definir as políticas, práticas e processos de RH para a empresa, orientando e acompanhando suas aplicações na EBE S.A. Os principais produtos dessa gerência geral são: Relatório Anual de RH, Indicadores de RH; Orçamento de RH; Cadeia de Valor do RH; Sistemas de RH; Estratégia de RH; Portfólio de Projetos e Iniciativas Estratégicas.

A gerência geral de Relacionamento (REL) é responsável por gerir o relacionamento institucional de RH da empresa com os órgãos públicos, demais entidades externas e as empresas subsidiárias que compõem a EBE S.A., assegurando atuação preventiva e proativa, conferindo maior autonomia e integração na gestão de RH nesse sistema. Os principais produtos dessa gerência geral são: Modelo de Relacionamento com Partes 
Interessadas; Sistema de Relacionamento com Partes Interessadas; Encontro com as gerências de apoio local de RH da EBE S.A.

A gerência geral de Remuneração (REM) é responsável por administrar e orientar as atividades referentes a relações trabalhistas, cargos e carreiras, remuneração, benefícios, reconhecimento e recompensas, de acordo com a legislação, necessidades e estratégias da EBE S.A. Os principais produtos dessa gerência geral são: Plano de Classificação e Avaliação de Cargos (PCAC); Tabelas Salariais; Tabelas de Diárias para Viagem; Participação nos Lucros (PL); Benefícios Educacionais; Convênios INSS e Previdência Complementar EBE.

A gerência geral da Universidade Corporativa (UC) é responsável pela capacitação corporativa dos empregados da empresa, bem como pela metodologia corporativa de gestão do conhecimento, a fim de promover, com visão sistêmica e integrada, o compartilhamento de conhecimentos da EBE S.A. e a capacidade de inovar, com o objetivo de alavancar a competitividade da empresa, contribuindo para sua sustentabilidade. Cabe a ela treinar e atualizar os empregados para que estes possam colocar em prática as competências necessárias ao alcance dos objetivos estabelecidos no planejamento estratégico e no Plano de Negócios da EBE S.A. Os principais produtos dessa gerência geral são: Programa de Formação; DL; Planejamento da Capacitação de Recursos Humanos (PCRH); Ensino a distância; Campus Virtual; Multiplicadores do Conhecimento; Manuais Técnicos; Livros Didáticos; Consultoria e Serviços Técnicos; Projeto Mentoria; Disseminação dos Conhecimentos adquiridos em eventos de PCE; Lições Aprendidas; Rodízio Técnico.

\section{Planejamento e iniciativas estratégicas de RH (2014-2019)}

Com base no Planejamento Estratégico da EBE S.A., e a partir dos desafios apresentados pelo seu Plano de Negócios 2019, o RH Corporativo atualizou seu Planejamento conforme abaixo (Figura 2).

Figura 2

\section{Planejamento de RH}

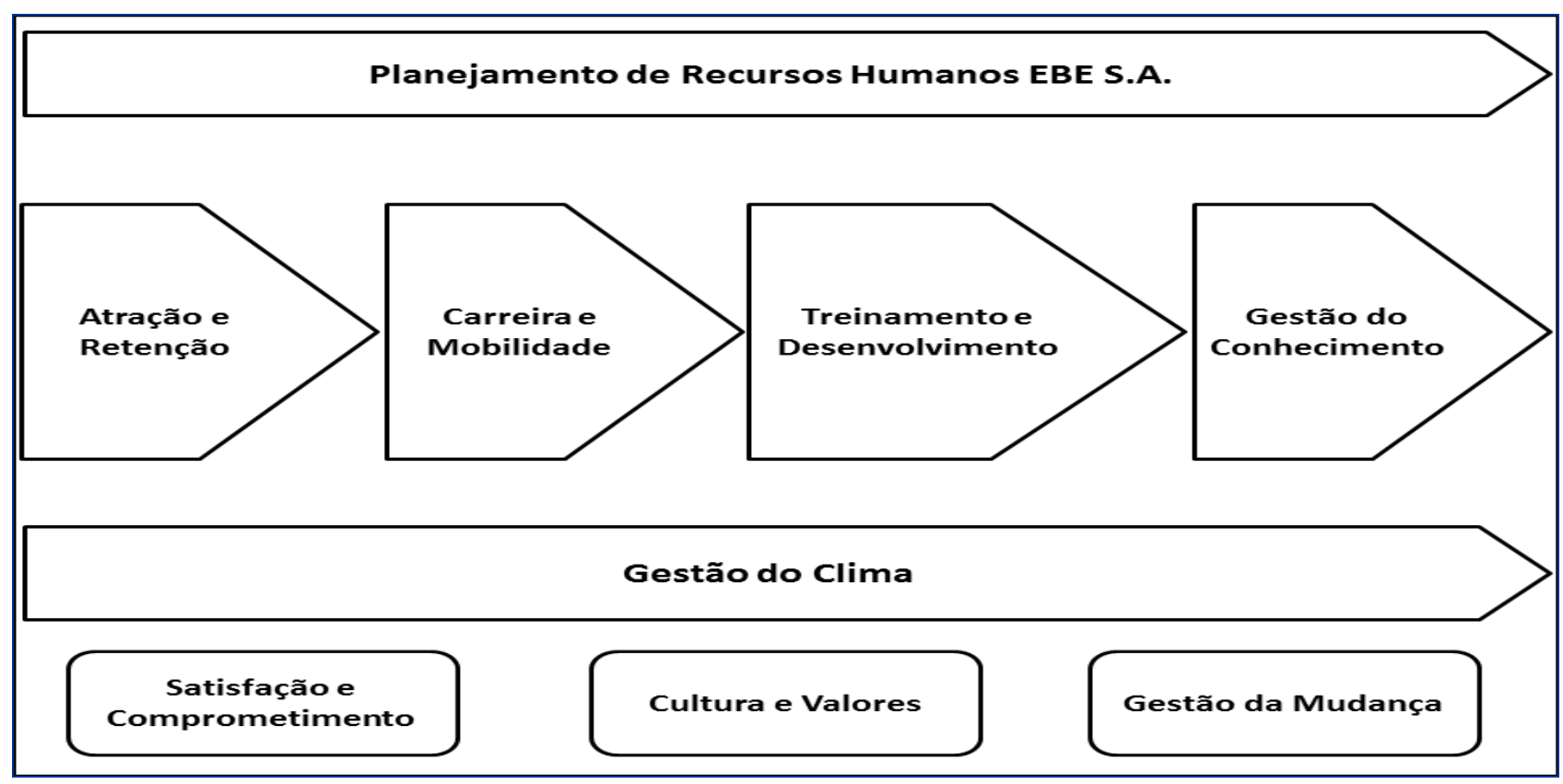

Fonte: Adaptado pelos autores com base no Planejamento de $\mathrm{RH}$ oficial da EBE S.A. 
As áreas que demandam maior atenção por parte do RH são Atração e Retenção, Treinamento e Desenvolvimento, Carreira e Movimentação, Gestão do Conhecimento - a Gestão do Clima deve ser considerada em todos os projetos e processos de $\mathrm{RH}$.

Nos meses de maio e junho de 2014, foram feitas apresentações para os empregados do RH Corporativo sobre os desdobramentos que o Plano Estratégico e o Plano de Negócios com visão 2019 trazem para a gestão de pessoas. Esses desdobramentos resultaram nas Iniciativas Estratégicas de RH (IERH 2014-2019), que nortearão a gestão de RH na EBE S.A. nos próximos cinco anos. Os temas prioritários são: Gestão do Conhecimento, Mobilidade, Planejamento da Força de Trabalho, Desenvolvimento Estruturado de Empregados, Alto Desempenho e Produtividade e Desenvolvimento e Sucessão de Líderes. Abaixo, observase o modelo esquemático do IERH 2014 - 2019 (Figura 3).

Figura 3:

IERH de 2014 a 2019

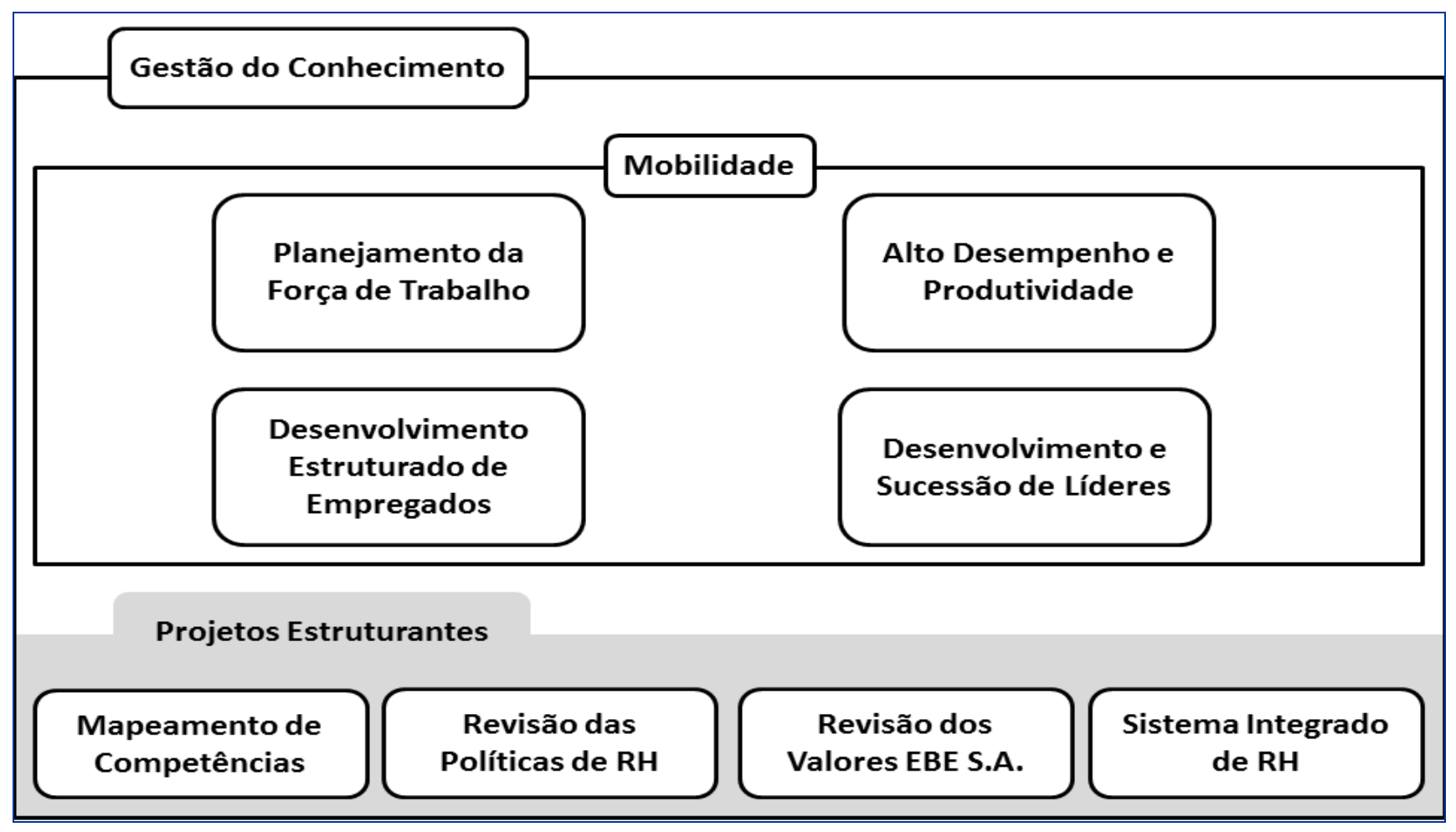

Fonte: Adaptado pelos autores com base no mapa de Iniciativas de RH oficial da EBE S.A.

As estratégias de RH relativas à Gestão do Conhecimento têm foco em promover a integração da gestão do conhecimento aos processos da empresa, buscando estabelecer a governança do processo, a fim de alcançar inovações e resultados sustentáveis. Já as estratégias relativas à Mobilidade têm foco em compatibilizar as necessidades organizacionais e interesses dos empregados na adequação do efetivo necessário para atender aos objetivos e às estratégias da empresa, propiciando agilidade e flexibilidade no atendimento das demandas de pessoal.

As estratégias de RH referentes ao Planejamento da Força de Trabalho têm foco em prover pessoal na quantidade e qualidade necessária para atender ao Plano de Negócios (PN) da EBE S.A. previsto para 2019, priorizando recursos disponíveis, considerando uma visão integrada da força de trabalho e otimizando recursos. Para alcançar os resultados esperados, o objetivo é definir estratégias e o planejamento da força de 
trabalho, considerando que o recrutamento, a seleção e a primeira alocação do empregado sejam feitos por perfil profissional.

Já as estratégias relativas ao Desenvolvimento Estruturado de Empregados possuem foco em sistematizar o processo de educação empresarial, garantindo a capacitação técnica e comportamental dos empregados na qualidade e tempo requeridos. Para tanto, o objetivo é revisar o programa de formação de novos empregados e o processo de desenvolvimento de soluções educacionais, bem como implementar trilhas de desenvolvimento para cada perfil profissional e um banco corporativo de ensino e aprendizagem, cujo objetivo é identificar e capacitar pessoas para atuarem como instrutores internos.

As estratégias referentes ao Alto Desempenho e Produtividade têm foco em reestruturar o processo de Avaliação de Desempenho (AD), de forma a atrelá-lo ao alcance das metas globais da empresa com o objetivo de estimular as pessoas para o cumprimento das metas do PN e aumento da produtividade. Já as estratégias de RH relativas ao Desenvolvimento e Sucessão de Líderes possuem foco em ter um corpo gerencial preparado para cumprir as metas do PN em tempo, na quantidade e com a qualidade necessárias. Para tanto, o objetivo é implementar um plano estruturado e contínuo de sucessão da liderança, bem como revisar o programa de DL.

Para que seja possível alcançar os resultados pretendidos, foram definidos quatro Projetos Estruturantes, cuja implementação é considerada como premissa para que o IERH logre êxito. O primeiro projeto estruturante trata do Mapeamento de Competências, e tem por objetivos concluir a identificação dos perfis profissionais atuantes em cada macroprocesso da EBE S.A., mapear as competências individuais específicas e seus atributos (conhecimentos, habilidades e atitudes requeridos) por perfil profissional, bem como disponibilizar os dados em sistema corporativo. O segundo projeto estruturante trata da Revisão das Políticas de RH, e tem por objetivo atualizar e adequar as práticas de gestão de pessoas às necessidades da empresa e dos empregados, tendo em vista as expectativas das novas gerações de empregados que entram na empresa, bem como os desafios que a EBE S.A. deverá enfrentar para cumprir seu Planejamento Estratégico 2019 (PE 2019).

O terceiro projeto estruturante trata da Revisão dos Valores EBE S.A., e tem por objetivo adequar os valores declarados pela empresa com o novo cenário oriundo do PE 2019, bem como verificar o alinhamento dos novos valores declarados com aqueles já praticados por gestores e empregados. O último projeto estruturante trata da implementação de um Sistema Integrado de RH, isto é, um sistema de informações integradas que contemple todos os processos de $\mathrm{RH}$, e tem por objetivo aumentar a qualidade, confiabilidade e disponibilidade das informações e indicadores de RH.

Nesse sentido, o IERH 2014-2019 indica qual o caminho o RH pretende trilhar nos próximos anos, de forma integrada e com um objetivo comum a todas as gerências que compõem os apoios locais de RH, bem como possibilita aos empregados que atuam em RH entender qual sua participação na realização dos resultados da EBE S.A. O cronograma dos projetos é acompanhado mensalmente em reuniões de análise crítica com o diretor de RH, que avalia as necessidades de ajustes no andamento dos projetos. Além disso, o RH realiza o monitoramento dos cenários externo e interno, que podem indicar a necessidade de inclusão de um novo projeto ou mesmo a alteração de um que já existe. A fim de aprimorar o acompanhamento, o RH deverá revisar seus indicadores estratégicos e suas metas, já em alinhamento ao PN 2014-2019.

\section{Resposta à problemática}

Relembrando a problemática: quais são as características que fazem da EBE S.A. uma Organização Inovadora Sustentável Resiliente? 
Para que a EBE S.A. seja uma organização inovadora, ela precisa ser capaz de inovar continuamente e também promover Inovações Radicais (redesenho radical e reengenharia de seus processos, produtos e serviços e papéis organizacionais). Dentro do conceito sociotécnico, a ideia é redesenhar o sistema, tornando-o mais complexo e evoluído. Entretanto, para isso, precisa, primeiro, desenvolver uma gestão estratégica de pessoas que, por sua vez, seja capaz de dar vida a um ambiente de aprendizagem organizacional que favoreça o surgimento de competências dinâmicas e que estimule o redesenho radical (inovação sustentável com ruptura) e também a inovação sustentável contínua.

Porém, para que a organização consiga gerar mudanças continuamente e com efetividade, ela vai precisar de uma gestão estratégica de pessoas que consiga dar suporte a essas mudanças sucessivas. Ou seja, uma gestão de pessoas com uma boa gestão resiliente, que faça com que a organização seja capaz de readaptar-se e recuperar-se, rapidamente, dos eventos disruptivos e transformadores. Trata-se da Gestão Estratégica de Pessoas também chamada Gestão por Competências.

Portanto, a fim de melhor responder à problemática, este tópico será dividido em três partes. Na primeira parte, serão destacadas as práticas, políticas e características da área de RH da EBE S.A. que atuam de forma a construir um ambiente de aprendizagem organizacional capaz de gerar uma força de trabalho que inova continuamente e que faz da EBE S.A. uma organização inovadora. Na segunda parte, será destacado o motivo pelo qual a EBE S.A. não é apenas uma organização inovadora, mas sim uma organização inovadora sustentável. E, por fim, na terceira parte, serão destacadas as características que fazem com que a EBE S.A. seja uma organização inovadora sustentável resiliente.

\section{Gestão Estratégica de Pessoas gerando aprendizagem e inovação}

A área de RH corporativa, atualmente, é responsável por coordenar os processos de gestão de pessoas por toda a empresa. Nesse sentido, o papel dessa unidade torna-se essencial, pois ela exerce uma gestão estratégica de pessoas a fim de formar uma organização com um corpo de colaboradores capaz de gerar inovação, criando vantagens competitivas sustentáveis. Abaixo são mencionadas algumas práticas, políticas e características do RH Corporativo que permitem que essa área crie um ambiente de aprendizagem organizacional e de inovação:

- o programa de atração, desenvolvimento e retenção de pessoas qualificadas na quantidade necessária, as quais possam gerar capacidades dinâmicas a partir de seu trabalho;

- a oferta de cursos, seminários e treinamentos por meio da Universidade Corporativa, como por exemplo, cursos de especialização em nível de pós-graduação lato sensu e cursos de educação continuada no Brasil e no exterior;

- o programa de DL, gerando gestores preparados para sustentar a estratégia;

- a área de Gestão do Conhecimento, que desenvolveu o Projeto Mentoria e o Programa de Sucessão de Líderes, que teve por objetivo preservar a continuidade da liderança;

- a Subcomissão de Gestão do Conhecimento, promovendo a integração e o alinhamento estratégico, propondo e analisando, em âmbito corporativo, diretrizes, metodologias e práticas que promovam a aprendizagem organizacional, inovação e melhoria contínua dos processos de Gestão do Conhecimento na empresa;

- o programa RH nas Unidades que tem por objetivo a troca de experiências;

- a Maratona do Conhecimento, que teve por objetivo promover a reflexão sobre o valor do conhecimento e levantar questões como melhoria nos processos, inovação e sustentabilidade;

- o processo de Gestão de Competências, mapeando e diagnosticando as competências; 
- a circulação de informação por meio do Blog RH e do SMS RH;

- o Programa Mobilidade, possibilitando a movimentação de pessoas de acordo com as competências do empregado e as competências requeridas pela vaga.

Essas práticas mostram como a área de Gestão de Pessoas da EBE S.A. contribui para o aprendizado organizacional. As práticas e políticas formam um ambiente de aprendizado em circuito duplo que torna as pessoas capazes de pensar sistemicamente, de forma a compreender como os sistemas produtivos funcionam e, a partir daí, buscar oportunidades que podem alavancar os resultados organizacionais.

\section{Organização Inovadora Sustentável}

As práticas da gestão estratégica do RH Corporativo citadas, acima, contribuem para gerar um ambiente propício à inovação e fazem da EBE S.A. uma organização inovadora. Porém, a EBE S.A. é, também, uma Organização Inovadora Sustentável, pois é capaz de inovar continuamente e de ser sustentável no nível econômico, social e ambiental, conforme definição de Barbieri, Vasconcelos, Andreassi et al. (2010).

A EBE S.A. integra o Dow Jones Sustainability Index (DJSI), o mais importante índice mundial de sustentabilidade, que avalia as melhores práticas de gestão econômica, social e ambiental do mundo. A organização obteve destaque principalmente nas áreas de Impacto Social nas Comunidades, Políticas e Sistemas de Gestão Ambiental e Liberações ao Meio Ambiente, o que comprova o fato da EBE S.A. poder ser considerada como uma Organização Inovadora Sustentável.

\section{Organização Inovadora Sustentável Resiliente}

Os dados acima mostram o motivo pelo qual a EBE S.A. pode ser considerada uma Organização Inovadora Sustentável. Contudo, uma organização inovadora sustentável tem que ser, também, uma organização resiliente.

Para que isso ocorra, o departamento de Pesquisa e Desenvolvimento vai inovar em termos de produtos, serviços e projetos, e o RH Corporativo dará suporte à organização de maneira a redesenhar os processos de RH e os papéis das pessoas para que a nova tecnologia seja efetivamente aproveitada, conforme definições de Fiksel $(2003,2006)$.

A seguir, serão expostas algumas características do RH Corporativo que fazem com que a EBE S.A. seja uma organização resiliente tanto no nível individual quanto no sistêmico. São elas:

- a capacidade de desenvolver e redesenhar projetos estruturantes como o planejamento da pesquisa e desenvolvimento, a mobilidade, o desenvolvimento estruturado de empregados e o reposicionamento da gestão do conhecimento;

- a existência de processos de gestão da inovação ligados à gestão do conhecimento, que desenha e reestrutura um ambiente de estímulo à inovação sustentável tanto com reengenharia radical quanto com melhoria contínua (exploration et exploitation, segundo SIMON, 1955), que promove a capacidade de inovar e de responder às mudanças causadas pela inovação;

- um programa de mapeamento de competências individuais específicas, que identifica perfis profissionais;

- o projeto estruturante que trata da Revisão das Políticas de RH, atualizando e adequando as práticas de gestão de pessoas às mudanças causadas pelo processo de inovação e às necessidades da empresa; 
- o programa de monitoramento do ambiente interno e externo, que pode identificar necessidades de redesenho dos procedimentos e das práticas da gestão de pessoas.

Ou seja, essas características da gestão de pessoas da EBE S.A. fazem com que o RH Corporativo dê suporte para que ela seja uma organização resiliente.

Portanto, uma Organização Inovadora Sustentável Resiliente, como a EBE S.A., terá um departamento de Pesquisa e Desenvolvimento (P\&D) que desenvolverá protótipos capazes de gerar mudanças transformacionais que resultarão em evolução tecnológica, reengenharia radical e redesenho. Isso permite que a organização inove com ruptura, gerando saltos quânticos na curva tecnológica (exploration, segundo SIMON, 1955). Em seguida, a organização vai desenhar os processos para que essa inovação seja amplamente utilizada (produção em escala). Contudo, o processo ainda não estará perfeito, exigindo que a organização seja capaz de "aprender fazendo" (learning by doing), o que permite a melhoria contínua dos processos por meio de inovações incrementais (exploitation, segundo SIMON, 1955) até que a organização chegue muito perto do "seis sigmas" (zero defeito), atingindo um patamar alto. Porém, quando a organização chegar nesse patamar, ela tem que estar pronta para fazer outra reengenharia radical para causar outro evento disruptivo a fim de gerar vantagem competitiva sustentável.

Uma Organização Inovadora Sustentável Resiliente, portanto, terá que saber lidar de forma efetiva com essas evoluções tecnológicas. Para tanto, além da organização ter uma área de P\&D capaz de realizar inovação técnica, ela também precisará ter uma área de gestão de pessoas capaz de gerar inovação social, adotando uma postura sociotécnica. Ou seja, quando ocorrer uma mudança transformacional, o departamento de RH terá que ser capaz de redesenhar os papéis sociais das pessoas e elas aprenderão a se comportar de uma nova maneira. Portanto, a inovação técnica em uma Organização Inovadora Sustentável Resiliente, como a EBE S.A., terá que ser acompanhada de uma inovação social, inovando, também, na capacidade de organizar suas competências internas.

Assim, a EBE S.A. é uma Organização Inovadora Sustentável Resiliente, pois ela conseguiu desenvolver um departamento de RH que cria práticas e políticas de gestão de pessoas capazes de fazer com que a organização responda com rapidez, eficiência e eficácia às rupturas tecnológicas, organizacionais e sistêmicas causadas pela reengenharia radical (inovação com ruptura) gerada pelo departamento de Pesquisa \& Desenvolvimento (P\&D), gerando vantagem competitiva sustentável.

\section{Referências}

ALBUQUERQUE, L. G. Estratégias de recursos humanos e competitividade. Administração contemporânea: perspectivas e estratégias. São Paulo: Atlas, 1999. 215-238p.

AMIT, R.; SCHOEMAKER, P. J. H. Strategic assets and organizational rent. Strategic Management Journal, v. 14, n. 1, p. 33-46, 1993.

ARGYRIS, C. On organizational learning. Cambridge (MA): Blackwell, 1992.

BARBIERI, J. C. et al. Inovação e sustentabilidade: novos modelos e proposições. Revista de Administração de Empresas, v. 50, n. 2, p. 146-154, 2010.

BARNEY, J. B. Firm resources and sustained competitive advantage. Journal of Management, v. 17, n. 1, p. 99-120, 1991. 
BARNEY, J. B.; HESTERLY, W. S. Administração estratégica e vantagem competitiva. 3.ed. São Paulo: Pearson/Prentice Hall, 2011.

BURNARD, K.; BHAMRA, R. Organisational resilience: development of a conceptual framework for organisational responses. International Journal of Production Research, v. 49, n. 18, p. 5581-5599, 2011.

DUTRA, J. S. (Org.). Gestão por competências: um modelo avançado para o gerenciamento de pessoas. São Paulo: Gente, 2001.

EISENHARDT, K. M. Building theories from case study research. Academy of Management Review, v. 14, n. 4, p. 532-550, 1989.

FIKSEL, J. Designing resilient, sustainable systems. Environmental Science and Technology, v. 37, n. 23, p. 53305339, 2003.

FIKSEL, J. Sustainability and resilience: toward a systems approach. Sustainability: Science Practice and Policy, v. 2, n. 2, p. 14-21, 2006.

FLEURY, A.; FLEURY, M. T. Estratégias empresariais e formação de competências: um quebra-cabeça caleidoscópio da indústria brasileira. 3. ed. São Paulo: Atlas, 2004.

GODOY, A. S. Pesquisa qualitativa: tipos fundamentais. Revista de administração de empresas, v. 35, n. 3, p. 20-29, 1995 .

HAMEL, G.; PRAHALAD, C. K. The core competence of the corporation. Harvard business review, v. 68, n. 3, p. 79-91, 1990

HAMEL, G.; PRAHALAD, C. K. Competing for the future. Harvard Business Review, v. 72, n. 4, 1994.

LACOMBE, B. M. B.; CHU, R. A. Políticas e práticas de gestão de pessoas: as abordagens estratégica e institucional. Revista de Administração de Empresas, v. 48, n. 1, p. 25-35, 2008.

LEI, D.; HITT, M.; BETTIS, R. Competências essenciais dinâmicas mediante a meta aprendizagem e o contexto estratégico. In: FLEURY, M. T.; OLIVEIRA JR., M. M. (Eds.). Gestão estratégica do conhecimento: integrando aprendizagem, conhecimento e competências. São Paulo: Atlas, 2001. 157-180 p.

LEONARD-BARTON, D. Core capabilities and core rigidities: a paradox in managing new product development. Strategic Management Journal, n. 13, p. 111-125, 1992.

MINTZBERG, H.; AHISTRAND, B.; LAMPEL, J. Safari de estratégia: um roteiro pela selva do planejamento estratégico. Porto Alegre: Bookman, 1998.

MOURA, M. C. C.; BITENCOURT, C. C. A articulação entre estratégia e o desenvolvimento de competências gerenciais. RAE Eletrônica, v. 5, n. 1, art. 3, jan./jun. 2006

PELAEZ, V. et al. Análise da capacidade dinâmica na indústria de máquinas para madeira: estudos de caso. Revista Brasileira de Inovação, v. 8, n. 2, p. 341-370, 2009.

SIMON, H. A behavioral model of rational choice. Quarterly Journal of Economics, v. 69, n. 1, p. 99-118, 1955.

TEECE, D. J.; PISANO, G.; SHUEN, A. Dynamic capabilities and strategic management. Strategic Management Journal, v. 18, n. 7, p. 509-533, 1997.

VASCONCELOS, F. C.; CYRINO, A. B. Vantagem competitiva: os modelos teóricos atuais e a convergência entre estratégia e teoria organizacional. Revista de Administração de Empresas, v. 40, n. 4, p. 20-37, 2000. 
VASCONCELOS, I.; MASCARENHAS, A. O.; VASCONCELOS, F. C. Paradoxos organizacionais, gestão de pessoas e tecnologia na Souza Cruz. RAE Eletrônica, v. 3, n. 2, p. 1-20, 2004.

VERGARA, S. C. Projetos e relatórios de pesquisa em administração. 14. ed. São Paulo: Atlas, 2013.

WEICK, K. E. Sensemaking in organizations. Thousand. Oaks (CA): Sage, 1995.

YIN, R. K. Estudo de caso: planejamento e métodos. Porto Alegre: Bookman, 2010. 